\title{
Theoretical and Practical-Actional Components of Intercultural Competence Development
}

\author{
VALI ILIE \\ Teacher Training Department, \\ University of Craiova, Romania \\ Email: Brainstorming71@yahoo.com
}

Tel: +40742353116

\begin{abstract}
Being lately understood as a dialogical and participative competence, the intercultural competence is a product of the network of interactions in time and space. The term "cultural" can name all the features, including the values and beliefs people grow with, the national, regional and local customs and in particular the attitudes and practices that affect the way they work. The aim of this study was to emphasize the role of intercultural competence development, process that can be achievable in any socio-cultural environment. The training area is one where teachers and learners interact, form and develop a range of skills, including the intercultural ones. We aimed at identifying the marks of a model of developing the intercultural competence and assessing the impact it has on a sample of 68 students who participated in the psycho-pedagogical training module during 2016-2017. The competence profile of the teacher also includes the intercultural competence, as communication in an intercultural context has an increasingly important role. Interculturality brings with it a new communication matrix, which requires an opening from the interpersonal and social communication to an intercultural communication. The proposed model is a methodological option which aims at a better communication between people of different cultures.
\end{abstract}

Keywords: Teachers, Training, Model, Culture, Communication.

\section{Introduction}

The education which is open towards values, which encourages cultural diversity and stimulates interaction, is an education that enables the formation and development of intercultural competence. The ability to understand the types of cultural barriers is an essential condition to make our diversity work. Beyond obstacles there are common goals and communication bridges, and school is one of the courts that contributes to the formation of intercultural competence. In the internal multicultural contexts, adaptation leads to mutual adjustment. The people in the dominant groups as well as those in the dominated ones are inclined to adapt their behavior to each other. Of course, the dominant group has the authority to require the non-dominant group to be the only one to adjust. The people in the dominant culture who experience cultural differences in a more ethnorelative manner are less likely to invoke this power. Instead, they are curious about the cultural differences and eager to experiment with other cultures. M. J. Bennett introduced the term ethnorelativism to designate the opposite of ethnocentrism. Being an adept of the experimental constructivism, he uses ideas specific to anthropology (Bateson, 1972, 1979), biology (Maturana and Varela, 1987; Varela, Thompson, and Rosch, 1991), psychology (Sapir and Whorf, 1956; Lakoff, 1987; Lakoff and Johnson, 1980, 1999), neuroanatomy (Damasio, 1999), communication (Barnlund, 1998) (apud Bennett, 2004). 
Getting stuck within a culture impoverishes the culture itself. Therefore, educational and cultural policies focus on the formation and development of intercultural competence. As the result of a long process, competence involves reorganization, integration at different levels of knowledge and experience, as well as continuous restructuring. There has been a recent increase in the interaction between people in different cultures, a diversification of relationships, and it is rightly said that "in the metropolitan areas of Europe there is no school or even a classroom where there are pupils from a homogeneous socio-cultural environment" (Neuner, 2012).

The principle of intercultural approach can be applied in at least two aspects (apud Cucoş, 2000): on a synchronous plan (for an adequate understanding of the individuals belonging to different cultures and living in the same historical context) and on a diachronic plan (as a means or catalyst for the meetings of cultures that belong to different time periods). These approaches send to the idea that interculturality is "a dynamic process of exchanges, dialogue, negotiation between groups, interactions and mutual influences, as well as the identification of a common language and a common space in which to achieve a good cohabitation of the representatives of different cultures" (Bocoş, 2017).

From an educational perspective, we are interested in the levels at which we can act in order to develop the intercultural dimension. One way to divide intercultural competences into separate skills is to distinguish between: savoirs (knowledge of the culture), savoir comprendre (skills of interpreting / relating), savoir apprendre (skills of discovery / interaction), savoir-être (attitudes of curiosity / openness), and savoir s'engager (critical cultural awareness), as Byram $(1997,2008)$ (UNESCO, 2013).

\section{Literature Review}

\section{The Concept of Competence}

Competence is a basic feature of a person who makes it possible to achieve high results in a particular job, role or situation. There are several levels of competence, some of the elements underlying them being harder to detect (e.g. motifs, character traits), and others more prominent. Their value increases as they assert themselves in time and once they enter socio-professional life, they widen the sphere of interaction and communication. Competence always needs a context of use that mobilizes resources. By themselves, the knowledge or the ways of action are not enough, but they need to be implemented in a practical activity, it is necessary to know how to act. This is one more reason to mobilize, as part of competence, a set of declarative knowledge (describing reality), procedural (prescribing the way to follow) and conditional (that show when to start an action).

The distinction between competences and capacities is subtle. We speak of capacity as part of an operation that does not refer to a family of identified situations, and its implementation and effectiveness can depend on contextualization and orchestration with other resources (in this sense, the capacity does not pretend to deal with the universality of a situation, but it is just an ingredient of it, a resource among others). When referring to actions, taking into account the whole of a situation that belongs to an identified family, by resorting to several resources of the subject (including capacity), we speak of competence. Unlike capacity, which is primarily defined by a set of operations and objects to which it applies, competence is first of all defined by a class of situations and a pragmatic relationship with these situations. By making the difference between what is achievable (capacity) and what, how and how much it is actually done (competence), current pedagogy includes the term of capacity into the one of competence.

Competence also includes abilities, understood as attributes to efficiently, easily, accurately and finely perform operations or intellectual/ mental or practical / motoric actions. Skills help refine competences by integrating new experiences of knowledge and action. Competence refers to what people can "do" (to the actional, practical and applicative field) rather than to what they "know". Ability is a construction centered 
on the manifested behaviors and appropriate application conditions. In fact, the difference between the two terms is one of complexity degree, of approach (behavioral versus constructivist).

The term of competence is often defined by its parallelism and relation to the term of pair, the term of performance. The distinction between competence and performance has been frequently debated over time. From a linguistic perspective, N. Chomsky separates competence (knowledge of a language) from performance (its usage). It describes competence as an idealized capacity, located in the psychological / mental characteristics or functions, and performance as the production of concrete statements. Competence develops and evaluates by the degree of accomplishing working tasks and translates into its effects (through resulted performance). Generally, competence is a group of specific performances of dispositions and abilities mobilized through social interaction, and performance is not so much the effect of competence as its cause. While performance (shown / observed in behavior) is measured directly, competence is a deduced ability. We share the hypothesis of the bi-directional relationship between competence and performance, a hypothesis according to which cognitive competences (and not only) guides performance, but are also modeled by it.

Competence also interacts with skill, understood as a result of learning and defined as an automated component of activity, consciously elaborated, strengthened by exercise, but developed without permanent conscious control. Those components of the activity that are always running the same, are frequently repeated and are practiced a lot, become automated. Skills are important conditions to accomplish complex activities that are deliberately and consciously carried out and which, in most cases, come within the sphere of competence. When it is associated with a functional need, learning becomes a habit. On the basis of acquiring more skills, ability is acquired, understood as an optimal combination of skills and knowledge and an easy restructuring for action in new situations.

By competence it is no longer understood only an applied capacity, the ability of an individual to appreciate a thing, on the basis of a thorough knowledge of the problem, in an informative sense (the restrictive sense), but rather the meaning of construct, the result of building pertinent combinations of the various internal and external resources, according to the context requirements.

Complex structures with instrumental value, skills are various: some are general (or transferable) and others are specific; some are centered on knowledge (savoir), others on attitudes (savoir-être) or on skills (savoirfaire). There are both cognitive and emotional competences, personal and social competences, strictly necessary competences, necessary and desirable competences, basic (basic, minimal, essential) competences and integration competences, entry competences (e.g. self-confidence) and exit competences (e.g. the presentation ability), etc. We can talk about objective skills (performance and the potential of performance measured by standard tests) and subjective competences (assessment of skills and competences needed to solve problems relevant to performance).

The formation and development of competences is determined by the social environment. Understood as a "fuzzy concept", competence depends on the context. Different cultural contexts influence the understanding of competence and there have been attempts (e.g. Boon and van der Klink, 2002 in the USA; Eraut, 1994 in the UK) to establish competence in terms of socio-cultural practices (apud Delamare Le Deist and Winterton, 2005). The greater the number of cultural contacts and the diversification of the interhuman relations becomes, the more the role of intercultural competence grows, and the educational partnerships can be a means of its development.

\section{Intercultural Competence}

Intercultural competence is the ability to communicate with people who originate in different cultures, the ability to mobilize knowledge, methods of action, but also emotional experiences, positive attitudes in solving certain situations of intercultural interaction. The essence of intercultural competence lies in a 
person's ability to adapt and the ability to reorganize the experience in an open, flexible, constructive and creative way. Intercultural competence is thus related to the way individuals are socially positioned in interactions (e.g. by nationality, gender, age, social status, etc.). It refers to the interaction between individuals and not to systems, such as societies or organizations. However, every interpersonal encounter takes place within a framework that is defined by the predispositions, purposes and rules (especially social norms) present in a given system.

The idea of "culture as a flow" brings to the fore the dynamics, the opening and the continuous change of it. The term "intercultural" describes what happens when members of two or more different cultural groups (of any size, at any level) interact or influence each other. The concept of intercultural competence encompasses a set of knowledge, abilities, skills and behaviors which, used harmoniously and complementarily, allow the individual to solve certain intercultural interaction situations. Intercultural competence is demonstrated in interacting with others, through effective communication and finding pertinent solutions to problems that appear in different intercultural contexts. A starting point on the path of acquiring intercultural competence is the attitude towards intercultural situations. This attitude is emotional and has motivational qualities (and, therefore, it is not easy to develop).

The possible intercultural conflicts can be changed or improved by acquiring intercultural competences, and the intercultural training takes into account the cultural positioning of countries, depending on different models. Scientist G. Hofstede proposes as dimensions of cultural specificity the following: distance to power (high or low), masculinity vs. femininity, individualism versus collectivism, avoidance of uncertainty (weak or strong), pragmatic vs. normative, and indulgence versus coercion. By implementing the specific training / development programs, we will be able to adapt our existing abilities and build new ones. Intercultural barriers are blockages that cannot be easily overcome. They require attention, time, and do not have to be put under pressure. Among the most well known intercultural barriers there is: language, value judgments, stereotypes, ethnocentrism, prejudices, discrimination, intercultural shocks and barriers caused by individual traits (low listening capacity, lack of openness or honesty and lack of learning abilities of a foreign language).

The classification of intercultural competences differs from one author to another, and specialized literature is generous in this respect: S. Lloyd and C. Härtel (2010) - cognitive, affective and behavioral competences; M. Harvey, N. McIntyre, M. Moeller, and H. Sloan (2012) - entry, managerial competences and competences based on transformation. A first classification was made in 1984 by B. H. Spitzberg and W. R. Cupach and includes the following types of competences: fundamental competences (for easy adaptation to new environments), social skills (including skills such as empathy, solution finding and the ability to compromise when needed, persuasion and self-confidence, teamwork, acceptance of differences between people in different cultures), competences referring to interpersonal interaction (interaction with foreign people), language competences (language skills according to specific grammar rules), communication competences (language competences), competences of interrelation (the ability to overcome and adapt to diversity). D. K. Deradorff (2006) builds the Pyramidal Model of Intercultural Competence, inserting the following elements: desired external outcome, desired internal outcome (informed frame of reference / filter shift), knowledge and comprehension, skills, requisite attitudes. Each component is as important as the others, since the existence of only a few or at least one component does not ensure the existence of intercultural competence.

Speaking about the proliferation of intercultural competences models, M. Barret enumerates the classification proposed in 2009 by Spitzberg and Changnon (Barret, 2013):

- Compositional models, which identify the various components of intercultural competence but do not specify the relations between them - these models therefore contain lists of the relevant attitudes, knowledge, skills and behaviours which together make up intercultural competence; 
- Co-orientational models, which focus on how communication takes place within intercultural interactions, and how perceptions, meanings and intercultural understandings are constructed during the course of these interactions;

- Developmental models, which describe the stages of development through which intercultural competence is acquired;

- Adaptational models, which focus on how individuals adjust and adapt their attitudes, understandings and behaviours during encounters with people from other cultural backgrounds;

- Causal path models, which postulate specific causal relationships between the different components of intercultural competence.

There are a number of models (processual, conceptual, structural, etc.) that have been used to specify the intercultural aspects of competence:

- The Model of Intercultural Communication Competence (B. D. Ruben, 1976) - creates a structural perspective on the resources of intercultural competence by listing some features, abilities and capacities needed in the effective management of inter-human relations (these are: manifestation of respect, orientation towards knowledge, empathy, interaction management, behavior of accomplishing a task, relational behavior, tolerance to ambiguity, position in interaction);

- The Model of Developing Intercultural Competences (W. Howell, 1982) - combines, from a procedural perspective, the involvement of awareness and the acquisition of intercultural competence on a fivestage evolutionary sequence: unconscious incompetence, conscious incompetence, conscious competence, unconscious competence; Intercultural Competence Development Model (J. Banks, 1988); is a stadial model whose reference is identity; the six stages are: ethnic psychological captivity, ethnic encapsulation, ethnic identity clarification, biethnicity, multiethnicity and reflective nationalism, globalism and global competence;

- The Model of Cultural Competence Continuity (T. Cross, 1989) - provides both an institutional and an individual framework to measure the progress made in various diversity initiatives; consists of six stages: cultural destructiveness, cultural incapacity, cultural blindness, cultural pre-competence, basic cultural competence and advanced cultural competence;

- The Model of Developing Intercultural Sensitivity (M. J. Bennet, 1993) - is a stadial model based on the ethnocentrism-ethnorelativism relation; it comprises the following stages: denial, defense, minimization, acceptance, adaptation and integration;

- The Holistic Model (G. Cheetham and G. Chivers, 1996) - is a holistic model of professional competence, comprising five sets of inter-connected competences and competencies (it includes five dimensions: cognitive competence, functional competences - skills or know-how, personal competency - behavioural competencies, know how to behave, ethical competencies, meta-competencies);

- The Model Of Developing Intercultural Maturity (P. M. King and M. B. Baxter Magolda, 2005) - is a conceptual model that identifies three levels of intercultural maturity (initial, intermediate and mature) from the perspective of three dimensions (cognitive, intrapersonal and interpersonal).

\section{Aspects of intercultural communication}

Intercultural competence is based on communication. Communication includes language, as well as nonverbal behavior, which involves the use of sounds (paralanguage), movements (kinesics), space (proxemic) and time (chronemics), to many aspects of material culture (food, clothing, objects, visual design, architecture) and can be understood as the active aspect of culture. Intercultural dialogue (which 
takes place between members from different groups) implies that participants agree to listen to and understand several perspectives, including those held by groups or individuals with whom they do not agree. The metaphor of the existence of certain "cultural baggage" refers to attitudes, patterns, judgments or expectations "packed" in our home cultures, which we carry with us. The pioneers in this field, such as E. T Hall and L. R. Kohls, have created specific exercises in order to help people examine their so-called cultural baggage.

As Hall said, "culture hides much more than it reveals, and, strangely enough, what it hides, it hides most effectively from its own participants. Years of study have convinced me that the ultimate goal of the study of culture is not so much the meaning of foreign cultures as the light that the study pours upon us" (Hall, 1998). E. Hall, the founder of intercultural communication as a discipline, has made a distinction between two aspects of culture: manifested and tacitly acquired. Through the manifested culture, he designates "words and numbers", and through the acquired one he understands the nonverbal aspects of communication, this being very situational and operating in accordance with unconscious rules that were not learned in the ordinary sense but were acquired in the process of growing or simply in different life situations. His statement that "culture is communication" is related to what is happening at the interface with the diversity of others.

The ultimate goal of intercultural learning is to transform our knowledge, skills and attitudes into competence and to develop flexibility and adaptability in intercultural communication. Associated with the idea of communication, culture is a subtle form of sociability. A process of symbolic interaction, this can be defined as all the representations and practices related to various identities. Identities can be personal, social and cultural. As individuals with multiple facets, related to the different "arenas", roles, etc., the identity list of each person is made up of all three.

Sometimes we use cultural identities to form stereotypes about our own cultural groups and about others. Stereotypes influence attitudes that can become prejudices. If we act on the line of a prejudice, we can easily reach discrimination. The stereotype is "the caricature of a social representation" (Preiswerk and Perrot, 1975, p. 239). It is stated that "in school, the numerous stereotypes spread about children who do not come from the dominant group spoil the relationship between the teacher and the student, and between the teacher and the family. For example, the prior assertion that some children from certain socio-economic environments and from certain groups do not "even" know their language and that they will have difficulties in learning the language they learn in, is a widespread and put forth stereotype, among other things, to justify some school difficulties" (Dasen, Perregaux, and Rey, 1999).

Focusing on cultural identity, we need to be aware of the fact that it can be over-generalized and it can lead to the following forms and symptoms:

- Stereotypes (the perceptual level) - our generalized visions towards a certain group of people sharing similar identities;

- Prejudice (the level of attitude) - our preconceived views (usually not based on real experiences or logical reasons) and related judgments about others;

- Discrimination (the behavioral level) - our unfair, exclusive or deliberate treatment which intentionally tries to harm different categories of people, usually based on perceptions of race, age, sex or other social and life style markers.

For each of these forms, the saying "It's not wrong, just different!" can help us try to understand the cultural logic behind the visible differences of certain cultural groups. Students bring to school different cultural experiences and practices that do not always coincide with the culture proposed by the school. It is suitable to "see culture as a formation that is built, among others, according to the environmental challenges, as a set of dispositions intended to respond to them" (Camillieri, apud Dasen, Perregaux, and 
Rey, 1999). As a result of the contacts between cultures there appear cultural practices, which bear their own meanings. Between the culture of the teachers and the culture of the pupils, of the rural and urban, of the advanced and underdeveloped, there are sometimes cleavages, stereotypes and prejudices are enhanced. Some communities are preoccupied with maintaining their power and territory and therefore they are closing themselves within their own limits. Others open out and create communication bridges.

Among the many areas of culture, E. T. Hall and other specialists on the subject have noticed behaviours related to how people use or respond to time and space in communication. The term "cronemic" was first used by E. T. Hall to designate the study of perception and use of time. Cultures differ significantly in relation to their attitude towards time and their ideas about its importance in human interactions. If time can be measured objectively by watches, the importance of time in everyday life is subject to interpretation. Cultural preferences for monochromatic (linear, sequential, analogic) and polychromic (simultaneous, multi-tasking, digital) temporal contrast differ from one culture to another. The same author also launched the term "proxemic", concerned about studying the social space as bio-communication. Proxemics investigates how the individual unconsciously structures space, interpersonal distances in daily transactions, organizing spaces in homes and buildings, and last but not least in configuring cities.

Thus, "communication in an intercultural context (...) is competent when fulfilling the objectives of an actor in a way that is appropriate to the context. The context involves multiple levels, including culture, relationship, place and position" (Spitzberg, 2000). The practice of cultural evaluation focuses on the determination of certain methods and tools to facilitate the quantification of cultural variables. It helps in the formation and development of intercultural competence. These include: intercultural communication workshops, simulation games, role plays, critical incidents, case studies, etc.

\section{Methods and tools used in the formation of intercultural competence}

\section{Value Orientation Method (VOM) - an instrument that helps understand cultural differences}

The method of guiding value is a method that helps people quickly understand the cultural differences. For those readers familiar with the Myers-Briggs indicator and the way to describe the types of people, VOM offers a similar method for describing types of cultures. The bases for VOM were developed in the 1940s and 1950s within the Harvard Value Project (Kluckhohn and Strodtbeck, 1961). The project team has assumed that it is possible to distinguish cultures based on how we relate to five common human concerns: human nature (what is the basic nature of humans?), the relationship man-nature (What is the right relationship with nature?), the meaning of time (How should we think best about time?), activity (What is the best kind of activity?), social relations (What is the best form of social organization?) (apud Gallagher, 2000).

As a scientific tool, VOM provides a way of measuring value differences, which can be later linked to other variables, such as participating in a training activity or preference for a professional development program. For example, an individual in a group that prefers hierarchical relationships (powerful command chain) cannot prefer a program that involves extensive collateral discussions to reach a decision. Cultural differences can affect us even in short exchange times. What we consider to be important can appear in what we say or what we expect others to say or how to answer.

\section{Rokeach Survey (RVS ) - an instrument of classifying values}

M. Rokeach (1973) has proposed a list of two sets of values: terminal and instrumental. Terminal values (ex. True Friendship, Mature Love, Self-Respect etc.) refer to the desired final states of existence, the goals that a person would like to achieve in his / her lifetime. They vary according to different groups of people in different cultures. Instrumental values (ex. Obedience, Helpfulness, Responsibility, Forgiveness) refer to preferred behavioral modes or means of achieving terminal values. Depending on the rank the subjects 
gave to the eighteen values in each category, M. Rokeach showed the presence of different cultural value patterns.

\section{The method of identifying value}

Not all of us fully subscribe to the cultural values around us. Some of us may consider ourselves a part of a distinct subculture (or of a co-culture), or just a circle of close friends, or we even want to be individually distinguished. Identifying the group we are part of helps us to consider what kind of values we represent under the influence of personal choices or directions. The identification of the group we are part of helps us to consider what kind of values we represent under the influence of choices or personal directions and to differentiate ethical behaviors (they have almost the same content in all cultures) from the emotional ones (they have different meanings in different cultures). It is considered that ,in highly individualistic countries, identity is often rooted in one's personal achievements, in one's uniqueness, experiences or personality, in one's special hobbies or interests. These are all identities that distinguish us from others. In fact, we need both types - related identities and unique identities. But often Asian cultures tend toward more common links, while Westerners emphasize their unique features" (Kulich, 2015). This method addresses differences in interaction and it is an adaptation after S. J. Kulich (2015). The suggested method calls for the answer to the following questions: Which of these types of values guides your relationships, decisions, or brings you satisfaction?, How do values influence the way you relate and communicate with others?, Which level is generally more important to you - group values or personal values?, Why?

This task is divided into four parts with clear requirements:

- Identifying the demographic aspects and characteristics of the closest cultural group we consider being part of: Demography and description of the cultural specificity;

- Choosing an important cultural value specific to our group and an individual value: Cultural value and personal value;

- Describing the content and specifying the implications of each aspect: explanation for each selected value;

- Creating your personal story: The personal story (it is related to cultural identity and includes the country of origin, area, the language used, customs and specific traditions).

\section{The Critical Incident}

Originally from the 1950s (J. Flanagan), the critical incident is a method of learning/ teaching and collecting research data. This collection and the accompanying facilitator/ activity guide seeks to help participants reflect on the complexity of cross-cultural exchanges, while at the same time facilitating their ability to distinguish and develop higher degrees of intercultural sensitivity. R. Wight defines critical incidents as "brief descriptions of situations where there is a misunderstanding, a problem or a conflict arising from the cultural differences among the interacting parties or where there is a problem of intercultural adaptation" (Wigh, 1995). The critical incidents apply intercultural concepts in real-life situations and they are useful when we intend to understand the details of interactive events.

Case analysis helps us confront confusing encounters, develop awareness and note the potential causes of intercultural misunderstanding. The degree of awareness and intercultural sensitization helps to understand and solve unfortunate intercultural events. D. Tripp (1993) claims that critical incidents appear to be typical rather than critical at first sight, but are rendered critical through analysis. He says that there are two important stages in the creation of critical incidents, namely: the production of an incident (observation, recall and description of what happened) and analysis (finding more general meaning of the incident and its evaluation). The value of critical incidents lies in the questions people should answer: What has actually happened?, How did I feel?, What do I think now?, What have I learned? 


\section{The Metaphor}

In 1986, G. Morgan published the "Images of Organization" in which she used the method of multiple metaphors to analyze organization in terms of key metaphors, such as "machine", "organism", "culture", "brain" and "political system". We all know organizations that have those characteristics. For example, when an organization is described as a machine, we picture mechanical moving parts, and see it as efficient, rational, and inflexible (Inkson, Dries, and Anderson, 2015). According to Lakovian theory, a metaphor is understood as a domain mapping which can instantiate metaphorical concepts. The mapping is between whole domains, not just individual concepts. This is evidenced by many expressions involving a variety of metaphorical concepts each united under the same source and target domains (apud Lakoff, 2008). The essence of metaphor is to understand and experience one kind of thing in terms of another.

There are different types of metaphors (e.g. implicit, extended, mixed, complex, etc.), most of which can be graphically represented. Among the most suggestive ones there are (apud Beer, 2003):

a) Forte fields

E. Schein uses the metaphor of "force fields" that are not directly visible but unifying and powerful. The metaphor sets culture beyond the individual control or personal characteristics.

b) Iceberg

The popular iceberg metaphor illustrates "hidden culture": the world of assumptions, habits, beliefs that may not be consciously articulated or taught. The metaphor implies danger, the necessity of having a skilled pilot, and justifies the use of cultural experts as there is much more to culture than meets the eye.

c) Mind Maps

There are two maps: the geographic and the mind-map. The geographic map represents the internal maps people have of their cultural terrain, knowing that "the map is not the territory" that reality is always vastly more complex than our mental renderings of it. The other is a mind-map, which depicts the network of associative links in our minds - knowledge triggered by a single word, for example, or the feelings and meanings we associate with a particular behavior. These associations are partly personal, partly collective. Culture in this metaphor is the map of a group's shared meanings and connections.

\section{d) Organism}

This biological metaphor sees culture as living, organic, in motion. There are boundaries between internal and external; the organism (and culture) survives by controlling that boundary (allowing nutrients and waste to pass the boundaries, but keeping out foreign intrusions). Within a culture there will be different functions and roles, yet there is a common beingness.

The diversity of metaphors highlights the interdisciplinary approach and tones the possibilities that help to decipher our own culture and the culture of others, contributing to the formation of intercultural competence. To the metaphors presented there are also added: Software of the mind, Chaos, Dolls and exotic natives, Compass or X mark, Jelly beans, Celebration, Spice Tray, Favorite pair of jeans, WindowThe Universe, Handbuzzer, Forest, Monet painting etc.

The metaphorical structure of the most fundamental concepts in a culture is in accordance with the fundamental values of that culture. Because there are physical experiences common to all people and experiences that differ from culture to culture, we can say that some metaphors are universal, while others are culturally specific. 


\section{Methodology}

Lifelong learning programs that essentially aim at personal and professional development invite participants to interact and reflect while they facilitate the accomplishment, among others, of the intercultural competence. In the context of educational partnerships and intercultural exchanges, the Department for Teacher Training from the University of Craiova organized in the academic year 20162017 a Psycho-Pedagogical Training Program for a number of 68 Italian students in order to be certified as teachers.

In this situation, we were interested in the intercultural competence of teachers and learners (demonstrated during the didactic activities) and the extent to which the model proposed by us is appreciated by the learners as useful in such situations.

The aim of our research is the analyses of intercultural competence from the perspective of its formation / development in teacher training programs.

In order to achieve our goal, we focused on the following research objectives:

- The analyses of the problem in the specialized literature;

- The planning of a model for the development of intercultural competence;

- The description of the proposed model from the perspective of future teachers training programs;

- The evaluation of the model proposed by the trainees;

- The development of some conclusions and suggestions for using this model of intercultural competence training / development.

\section{Planning the Model for the Development of Intercultural Competence}

Considering the formation and development of intercultural competence from a systemic point of view, we planned an integrative model for the development of intercultural competence that is able to combine the theoretical, practical and applicative components (ethical behaviours), starting from the necessity to include cognitive (declarative and procedural), affective, actional and socio-cultural elements.

Starting from the essence of the key concepts (competence, interculturality), from the specification of some types of competences and from the identification of the elements of intercultural competence, we have made a list of the models of intercultural competence. Considered from a conceptual, procedural or structural perspective, the inventoried models are based on communication, and that is why we have given intercultural communication a special place.

The main objectives we have reminded (to teachers and learners) in the targeted training program are as follows:

- Acquiring cultural knowledge that relate both to general culture and culture in the field of specialty, paying particular attention to the invisible cultural elements, which are the hidden part of an iceberg;

- Awareness of cultural differences and valorization of the cultural specificity;

- Analyzing situations from different cultural perspectives;

- Solving problems caused by cultural differences;

- Engaging in different cultural practices;

- Cultivating intercultural attitudes that include tolerance, respect, curiosity and empathy towards other cultures;

- Developing the intercultural sensitivity of learners. 


\section{Structure}

- Cognitive elements: declarative and procedural (knowledge, metacognitive rules, metacognition)

- Affective elements (attitudes, feelings, motivations)

- Actional elements (abilities, skills, capacities, competencies)

- Social elements (relationing, collaboration, communication, participation, partnership)

- Cultural elements (values, creations from different domains)

\section{$\sqrt{ }$}

\section{Referential}

$>$ Knowledge about own culture and its practices

$>$ Knowledge about the values and practices specific to other cultures

$>$ Ability to understand and interpret cultural specifics and practices

$>$ The ability to apply cultural practices in different situations

$>$ Ability to recognize cultural identity (public, personal and psychological characteristics)

$>$ Capacity to analyze and synthesize situations, intercultural behaviors

$>$ Capacity to evaluate intercultural situations, behaviours and practices

$>$ Adaptation to new situations, flexibility, openness

$>$ Appreciation of one's own culture and other cultures

$>$ Engaging in intercultural practices

$>$ Responsibility to highlight common points

$>$ Respect for cultural differences

$>$ Overcoming the cultural shock (psychological and physical)

$>$ Development of intercultural sensitivity

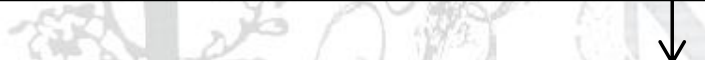

\section{Methods}

- Specific intercultural education methods (value identification, critical incident, metaphor, etc.)

- Classical and modern teaching methods (observation, heuristic conversation, problem-solving, dramatization, role play, project, exercise, simulation, computer-assisted training, etc.)

- Methods and tools of constructivist nature (critical prejudice inventory, negative influence octacle, matrix to solve a situation, dialogue between the optimist and the pessimist, diagram for the support of the viewpoints, etc.)

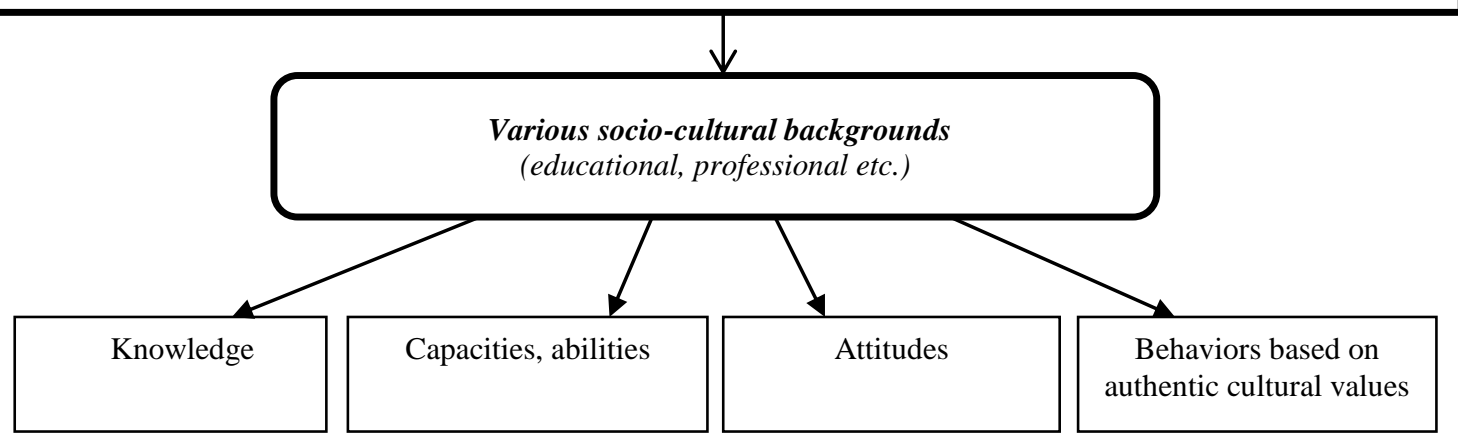

Figure 1. The integrative model for the development of intercultural competence 


\section{Description of the integrative model for the development of intercultural competence}

The proposed model is based on a series of cognitive, affective, actional, social and cultural elements that represent the referential from which the descriptors of intercultural competence derive. It has an orientation role and it has the practical advantage of arguing the value judgment. The integrative model was presented and explained to the learners at the beginning of the training program when they were trained about the way the activities were going to unfold in accordance with the intercultural dimensions offered by the curricular content.

The methods used during the training program are methods specific to intercultural education, instructive and educational methods (with an active and participative role) and constructivist training methods/ tools. They are used to achieve the established objectives and we have used them during the circulation of the course contents "The Sociology of Education" (e.g. Social Groups and Organizations, Culture, Socialization, Social Interaction and Social Networks, Deviance and Social Control). The school environment is one that is favourable to the development of intercultural competence, and the appurtenance of the educational actors involved is different, so that the activities have been carried out on the basis of the blending between the teachers' culture and the trainees' culture, of the cultures from two different countries, of male and female culture, of different professional cultures (legal field, arts field, medical field, etc.). Also on the axis of diversity is the pedagogical preoccupation to provide students with the opportunity to communicate and cooperate with the others inside some heterogeneous groups. We had a direct interest in the knowledge (treated from different cultural perspectives), the capacities, the abilities (analysis and synthesis, extrapolation, transfer, problem solving, related to objectives and tasks of intercultural nature), intercultural attitudes and behaviors that are axiologically based.

We have focused on open, multidirectional communication and have capitalized on a large register of reactions from the learners (cognitive, emotional, attitudinal, etc.). In order to contribute to the development of good practices in the field of intercultural relations, the model develops intercultural competence and encourages the dialogue of cultures viewed from the perspective of intercultural education.

\section{The Evaluation of the Proposed Model made by the Students}

At the end of the training program we applied a questionnaire to the students which is structured on the following items:

Item 1. Do you know any model of intercultural competence formation/ development?
a) Yes
b) No

Item 2. From the perspective of developing intercultural competence, our model is:
a) Totally inefficient
b) Inefficient
c) Quite efficient
d) Efficient
e) Very efficient

Item 3. What are the advantages of the proposed model?

Item 4 . What are the disadvantages of this model? 
Item 5. What is the category of methods that you consider to be most effective in developing intercultural competence?

The items of the questionnaire are aimed at collecting information from the learners on the impact of our proposed model on the activities carried out, as the intercultural approach is a premise, an objective, a process and a result materialized in intercultural dialogues and practices.

\section{Results}

For the item 1, the learners gave the following answers:

a) Yes: $16(23.53 \%)$

b) No: $52(76.47 \%)$

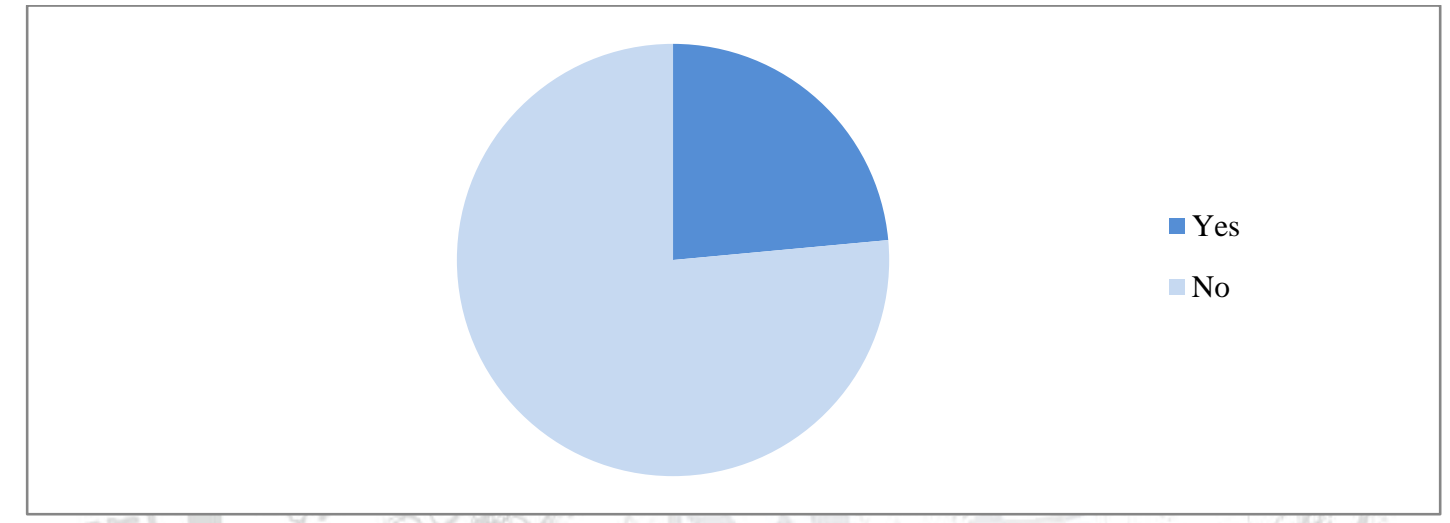

Figure 2. The identification training / developing models of intercultural competence

Considered in terms of efficiency, the proposed model was appreciated by the learners as a result of the answer to item 2 . Thus we registered the following scores:

a) Total inefficient: $2(2.94 \%)$;

b) Inefficient: 5 (7.35\%);

c) Quite efficient: $27(39.71 \%)$;

d) Efficient: $23(33.82 \%)$;

e) Very efficient: $11(16.18 \%)$.

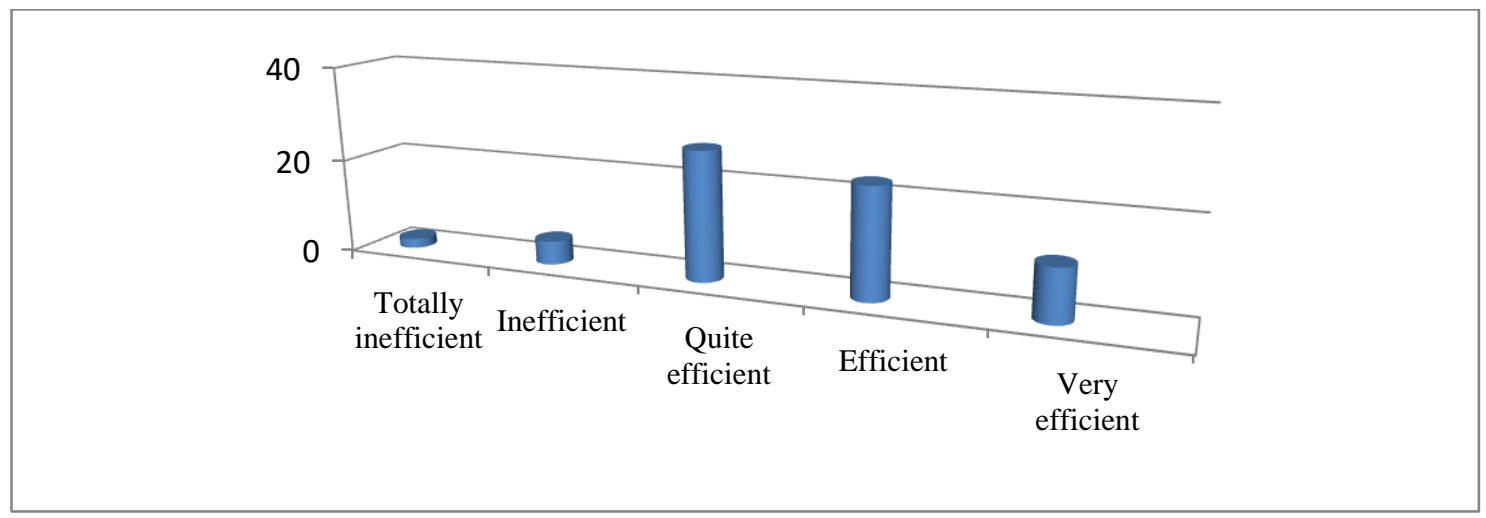

Figure 3. The estimation of the model in terms of efficiency 
Item 3 addresses the advantages training/ developing model of intercultural competence. Most of the answers provided by the learners capture the following positive aspects:

- They provide an overview of the components of intercultural competence;

- They identify the methodology that can be used;

- They combine the theoretical aspects with the practical dimension;

- They are oriented towards the formation/ development of intercultural competence

Among the answers given to the question of item 4, the trainees identified the following disadvantages, limits:

- They do not pursue very clearly the objectives pursued;

- They do not exemplify the learning tasks that can be used;

- They do not specify the way the evaluation is made.

Because item 5 calls for the identification of the category of methods that the learners consider to be the most efficient in the development of intercultural competence, we recorded the answers obtained in descending order of frequency:

a) Methods specific to intercultural education: 36 (53\%);

b) Classical and modern teaching methods: $10(15 \%)$;

c) Methods and tools of constructivist nature: $22(32 \%)$.

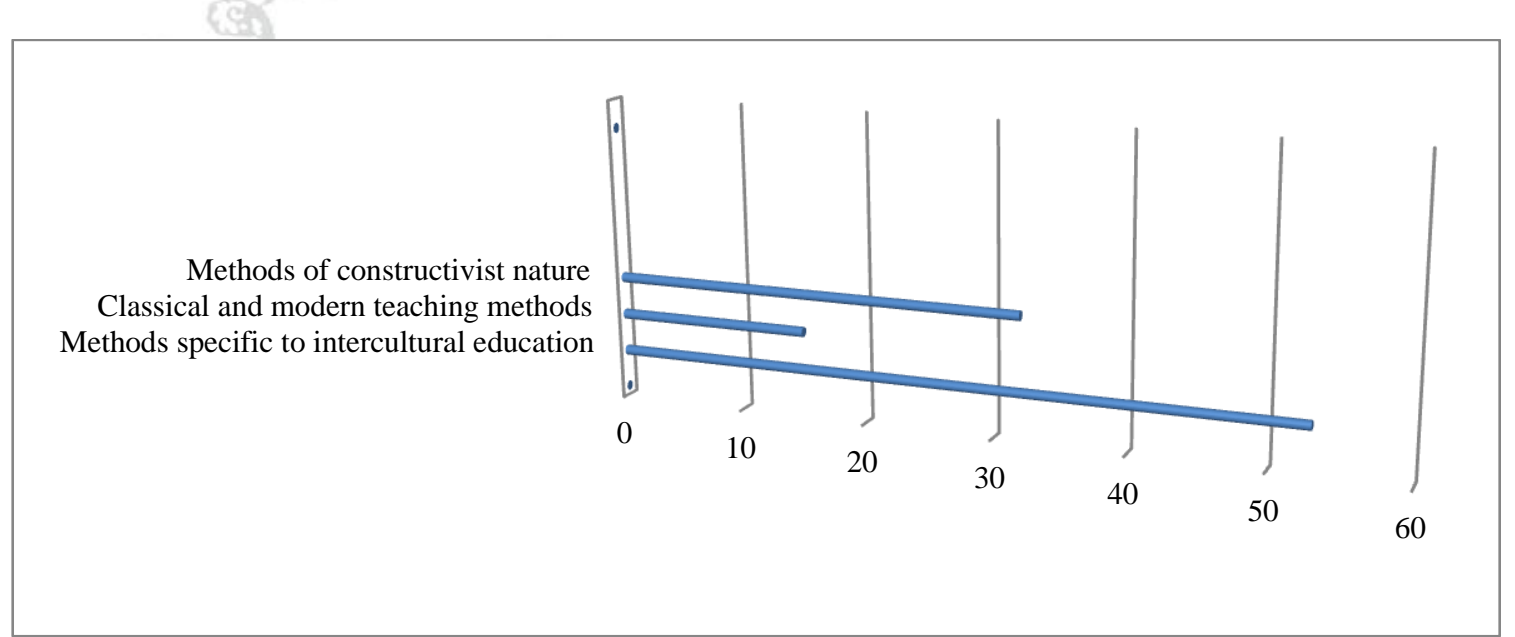

Figure 4. The frequency polygon of the chosen methods selected in the development of intercultural competence

\section{Discussion}

After processing the results, we used the qualitative analysis of the answers and found the following:

- Most learners (over 76\%) said they did not know a pattern of training / developing intercultural competence. Only $16(23.53 \%)$ responded affirmatively, but we consider that this is not a particular issue, given that few of them do teaching and the rest have a minimal classroom experience.

- The proposed model may be useful in conducting instructional and educational activities for both learners and teachers. 50\% of the students appreciate that the Integrative Model of Training / Developing Intercultural Competence is efficient and highly effective. There are also subjects who 
consider the model ineffective (7.35\%) and totally ineffective $(2.94 \%)$, which means that it is improvable.

- By its own conception, the model provides an overview of the components of intercultural competence and tries to exploit the formative valences of the training. The content of the subject "Sociology of Education" allows practical and applicative tasks to be put in place, enabling learners to interact, communicate and develop their intercultural competence. Also, specifying the methodology

- characteristic to intercultural education is one of the advantages, the proposed model allowing openings to other interactive tools and techniques, used individually, in groups or frontally.

- Any intervention involves assuming risks, identifying gaps or errors. That is why we were interested in finding out what are the main limitations or disadvantages of our model. One of the deficiencies found is that the model does not operationalize very clearly the objectives pursued. We have built up a referential, understood as an axiological reference system which is also theoretical and has the role of scientifical substantiating. It consists of a set of elements that function as a landmark system. We understand the referential as a normative and operational dimension of evaluation, serving as a basis for assessing intercultural competences. The model could be improved by building performance descriptors (hierarchical explanatory details of the expected performance), similar to the procedures for operationalizing the objectives. In terms of learning tasks, they remain at the discretion of the teacher and learners, their content adapting themselves to the specifics of the educational subject.

- There are a number of categories, of methods (of knowing personality, of research, of stimulating creativity, of moral education, etc.), but the ones mentioned in the last item seem most appropriate for the purpose proposed in this research. More than half of the subjects chose methods specific to intercultural education (53\%), which means they activate, capture attention, adapt to the content, and contribute to the achievement of the declared goals.

\section{Conclusion}

The process of forming and developing intercultural competences is in close connection with the attitudes, abilities and self-culture of the individual. Depending on the multitude of interactions with other cultures and the consistency of the accomplishment of the specific activities, the individual acquires more and more types of competences, both in the external environment and in the internal environment. Training programs differ from one researcher to another and from one training center to another. It is worth observing that some programs focus more on knowing foreign culture and its implications, and others on relations and communication.

The model we have put together, implemented and evaluated in didactic activity is an option of training/ developing intercultural competence. Further research is needed to clarify all aspects by filling in the categories of unchecked individuals and clarifying the contradictions. Our own culture and the way we see the world will dictate attitudes and behaviors in our personal and professional life. Individuals are not born interculturally competent, but become competent through education and life experiences. Twinning relationships between schools in different countries, student exchanges or teaching staff are additional strategies to meet the demands of intercultural education. The current European societies, both ethnically and culturally diverse, and from the perspective of identities and interests, are the arena of cohabitation with more and more obvious alterities.

\section{References}

Banks, J. A. (1988). The stages of ethnicity: Implication for curriculum reform. In J. A. Bansks (Ed.), Multiethnic education: Theory and practice (pp. 193-202). Boston: Allyn and Bacon.

Barrett, M. (2013). Intercultural competence: A distinctive hallmark of interculturalism? In M. Barrett (Ed.), Interculturalism and Multiculturalism: Similarities and Differences (pp. 147-168). Strasbourg: Council of Europe Publishing. 
Beer, J. E. (2003). A picture is worth a thousand word. Metaphors for Culture, In Culture at Work. Culture, http://www.culture-at-work.com/concept2.html

Bennett, M. J. (1993). Towards ethnocentrism: A developmental model of intercultural sensivity. In R.M. Paige (Ed.), Education for the intercultural experience (pp. 21-71). Yarmouth, ME: Intercultural Press.

Bennett, M. J. (2004). Becoming interculturally competent. In J. Wurzel (Ed.), Towards multiculturalism: A reader in multicultural education (pp. 62-77). Newton, MA: Intercultural Resource.

Bocoș, M. (2017). Dicționar praxiologic de pedagogie. Vol. III (I-L). Pitești: Editura Paralela 45.

Chetham, G. \& Chives, G. (1996). Towards a holistic model of professional competence. Journal of European Industrial Training, 20(5), 20-30.

Cross, T., Bazron, B., Dennis, K., \& Isaacs, M., (1989). Towards A Culturally Competent System of Care. Volume I. Washington, DC: Georgetown University Child Development Center, CASSP Technical Assistance Center.

Cucoș, C. (2000). Educația. Dimensiuni culturale și interculturale. Iași: Editura Polirom.

Dasen, P., Perregaux, Ch., \& Rey, M. (1999). Educația interculturală. Experiențe, politici, strategii. Iași: Editura Polirom.

Deardorff, D. K. (2006). The Identification and Assessment of Intercultural Competence as a Student Outcome of Internationalization at Institutions of Higher Education in the United States. Journal of Studies in International Education, 10, 241-266.

Delamare Le Deist, F. \& Winterton, J. (2005). What is competence? Human Resource Development International, 8(1), 27-46.

Gallagher, T. J. (2000). Value orientations and conflict resolution: Using the Kluckhohn Value Orientations Model. In K. W. Russo (Ed.), Finding the middle ground: Insight and applications of the Value Orientations Method. (pp. 185-194). Yarmouth, ME: Intercultural Press.

Inkson, K., Dries, N., \& Arnold, J. (2015). Understanding Careers. London: Sage

Hall, E. T. (1998). The power of hidden differences. In M. J. Bennett (Ed.), Basic Concepts of Intercultural Communication. Selected Readings. (pp. 53-68), Vermont: Intercultural Press.

Harvey, M., McIntyre, N., Moeller, M., \& Sloan, H. (2012). Managerial Self-Concept in a Global Context: An Integral Component of Cross-Cultural Competencies. Journal of Leadership \& Organizational Studies, 19(1), 115-125.

Howell, W. S. (1982). The empathic communicator. University of Minnesota: Wadsworth Publishing Company.

King, P. M. \& Baxter Magolda, M. B. (2005). A Developmental Model of Intercultural Maturity. Journal of College Student Development, 46(6), 571-592.

Kluckhohn, Fr. \& Strodtbeck, Fl. (1961). Variations in value orientations. Evanston, Il: Row, Peterson.

Kulich, S. J. (2015). Levels of identity in interaction. The SISU Intercultural Institute "Intercultural Communication" FutureLearn course reading (updated from the original in English Salon, April, 2002). Retrieved from https://www.futurelearn.com/courses/intercultural-communication?

Lakoff, G. (2008). The neural theory of metaphor. In R. Gibbs (Ed.), The Cambridge Handook of Metaphor and Thought. (pp. 17-38), New York, NY: Cambridge University Press.

Lloyd S. \& Härtel, C., (2010). Intercultural competencies for culturally diverse work teams. Journal of Managerial Psychology, 25(8), 845-875.

Neuner, G. (2012). The dimensions of intercultural education. In J. Huber (Ed.), Intercultural competence for all: preparation for living in a heterogeneous world. (pp. 11-49), Strasbourg: Council of Europe Publishing.

Preiswerk, R. \& Perrot, D. (1975). Ethnocentrisme des enfants de travailleurs migrants en Europe: l'interculturalisme et la formation des enseignants. Strasbourg: Conseil de l'Europe.

Rokeach, M. (1973). The nature oh human values. New York: Free Press.

Ruben, B. D. (1976). Assessing communication competency for intercultural adaptation. Group and Organizational Studies, 1(3), 334-354.

Spitzberg, B. H. \& Cupach, W. R. (1984). Interpersonal Communication Competence. Beverly Hill CA: Sage. 
Spitzberg, B. H. (2000). A model of intercultural communication competence. In L. A. Samovar \& Porter, R. E. (Eds.), Intercultural communication: A reader. Ninth Edition. (pp. 375-387). Belmont, CA: Wadsworth.

Tripp, D. (1993). Critical Incidents in Teaching. Developing Professional Judgement. London: Routledge. UNESCO (2013). Intercultural Competences. Conceptual and Operational Framework. France: Paris.

Wight, A. R. (1995). The critical incident as a training tool. In S. M. Fowler (Ed.), Intercultural sourcebook: Cross-cultural training methods. Volume 1 (pp. 127-140). Yarmouth, ME: Intercultural Press.
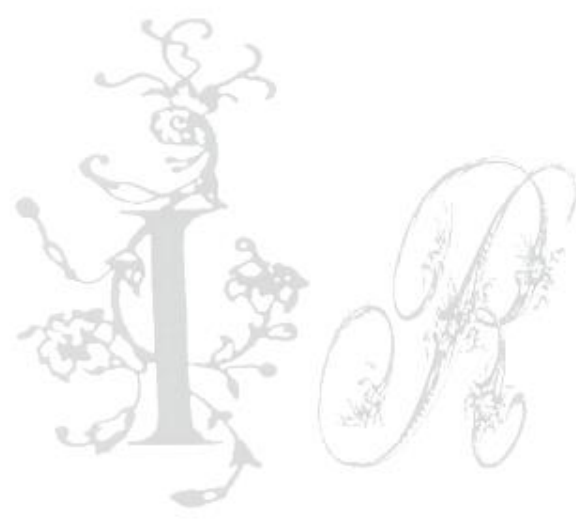